\title{
VALIDITAS DAN RELIABILITAS SKALA KARAKTER SOPAN SANTUN PADA SISWA SMA KELAS X DI NGANJUK
}

\author{
Ula Azizah ${ }^{1}$, Santy Andrianie ${ }^{2}$, Laelatul Arofah ${ }^{3}$ \\ ullaazizah407@gmail.com, sandrianie.putranto@gmail.com, laelatularofah91@gmail.com \\ Bimbingan dan Konseling-FKIP \\ Universitas Nusantara PGRI Kediri
}

\begin{abstract}
Manners character of courtesy is very necessary for students in each individual. Students who have a strong character of manners will not lead to moral decline and will become a hallmark of students, namely students who have high polite character.To be able to find out how big the students' character is, an instrument is needed in the form of a polite character scale. With this scale, it is hoped that students will map their polite and reliable character. This study aims to determine the validity and reliability of the politeness character scale. The development of this polite character scale uses six steps of compiling instruments from Riduwan which are modified according to needs. The results of the analysis of the validity and reliability test using product moment correlation and Cronbach's alpha obtained 29 valid statement items with an $r$ alpha reliability of 0.928 meaning they are in the high category, which means that the polite character scale can be used by BK teachers to map the polite character of high school students $X$.
\end{abstract}

Keywords: manners character, validity, reliability

\begin{abstract}
Abstrak
Karakter sopan santun sangat diperlukan bagi peserta didik dalam diri setiap individu. Siswa yang memiliki karakter sopan santun yang kuat tidak akan membawanya pada penurunan moral dan akan menjadi ciri khas pada diri peserta didik yaitu peserta didik yang berkarakter sopan santun tinggi. Untuk dapat mengetahui seberapa besar karakter sopan santun siswa diperlukan sebuah instrumen berupa skala karakter sopan santun. Dengan adanya skala tersebut diharapkan siswa akan terpetakan karakter sopan santunnya secara valid dan reliabel. Penelitian ini bertujuan untuk mengetahui validitas dan reliabilitas skala karakter sopan santun. Pengembangan skala karakter sopan santun ini menggunakan enam langkah penyusunan instrumen dari Riduwan yang dimodifikasi sesuai dengan kebutuhan. Hasil analisis uji validitas dan reliabilitas menggunakan korelasi product moment dan alpha cronbach diperoleh 29 item pernyataan valid dengan reliabilitas $r$ alpha sebesar 0,928 berarti berada dalam kategori tinggi yang artinya skala karakter sopan santun dapat digunakan oleh guru BK untuk memetakan karakter sopan santun siswa SMA kelas X.
\end{abstract}

Kata Kunci: karakter sopan santun, validitas, reliabilitas

\section{PENDAHULUAN}

Setiap peserta didik memiliki karakter yang berbeda-beda. Salah satu karakternya adalah sopan santun. Sopan santun adalah salah satu jenis karakter yang berkaitan dengan manusia satu dan yang lainnya. Siswa yang memiliki karakter sopan santun rendah terlihat dari sikap moral yang ada pada dirinya. Pada saat ini terdapat banyak siswa disekolah yang menunjukkan melakukan tindakan yang mengarah pada penurunan karakter sopan santun baik dalam berbahasa atau dalam berperilaku. Dalam diri peserta didik tertanam nilai, etika yang berbeda pula, sehingga akan muncul sikap moral yang berbeda pula.Setiap individu memiliki karakter sopan santun dalam dirinya, yang menjadi pembeda pada setiap manusia satu dengan 


\section{Efektor, Volume 8 Issue 2, 2021, Pages 167-175 \\ Ula Azizah1,Santy Andrianie2 ${ }^{2}$, Laelatul Arofah ${ }^{3}$}

yang lainnya. Bentuk tindakan penguatan dari karakter sopan santun harus dikuasi oleh setiap diri individu dengan tidak melakukan tindakan-tidakan yang menunjukkan penurunan karakter sopan santun. Karakter sopan santun sangat berperan penting untuk meningkatkan kualitas sumber manusia, terutama bagi peserta didik atau siswa di sekolah.

Dalam etimologi, karakter berasal dari bahasa latin character, yang artinya watak, tabiat, sifat-sifat kejiwaan, budi pekerti, kepribadian dan akhlak (Fitri, 2017:20).Karakter berarti tabiat, watak, sifat-sifat kejiwaan, akhlak serta budi pekerti yang membedakannya dengan orang lain (Poerwadarminta, 2007).Zubaedi (2011) berpendapat karakter ialah cara berpikir dan bertingkahlakumanusia yang didalamnya memiliki ciri khas yang digunakan untuk dapat hidup serta bekerjasama dengan orang lain, baik di lingkungan keluarga, masyarakat serta negara. Muslich (2011) juga menjelaskan bahwa karakter merupakan sekumpulan tata nilai yang berorientasi terhadap suatu sistem yang melandasi pemikiran, sikap, dan perilaku yang ditampilkan.Dari beberapa uraian pengertian karakter, disimpulkan bahwa karakter ialah sekumpulan tata nilai dalam diri manusia yang meliputi tabiat, watak, kebiasaan, budi pekerti, sifat-sifat kejiwaan, kepribadian, akhlak, yang tertanam dalam jiwa manusia yang menjadi ciri khas individu membedakan dirinya dengan orang lain.

Menurut Bertens (2013:7), Etiket artinya adalah sopan santun, yang didalamnya mencakup perilaku yang harus dilakukan manusia. Etiket berkaitan dengan tindakan perilaku manusia yang dapat atau tidak dapat dilakukan berdasar dengan sesuai dengan norma yang berlaku. Norma kesopanan bersifat relatif, artinya disetiap lingkungan tempat tinggal memiliki aturan dan norma kesopanan yang berbeda-beda (Larasati, 2020). Sopan santun dapat diartikan sebagai aturan tidak tertulis yang mengaturtata cara manusia dalam hal bersikap dan berperilaku yang seharusnya dilakukan (Suryani, 2017).

Etiket adalah tata cara yang baik untuk meningkatkan kenyamanan bagi manusia serta lingkungan.Etika berasal dari bahasa Prancis "etiquette" yang berarti sebuah tata cara yang mengatur hal baik yang dapat diimplikasikan pada masyarakat secara luas. Contoh tindakan yang dapat melatih seseorang untuk mempertajam sopan santun didalam dirinya antara lain, mengucapkan terimakasih jika sedang menerima sesuatu, mengucapkan kata tolong jika akan sedang meminta bantuan pada orang lain, serta meminta maaf jika melakukan kesalahan (Pane dalam Aminah, 2019). Sopan santun merupakan sikap dan tindakan berperilaku manusia yang sesuai dengan adat istiadat atau aturan tata cara yang berlaku pada masyarakat (Zuriah, 2007:84).Berdasarkan uraian pengertian sopan santun diatas, dapat ditarik kesimpulan jika sopan santun merupakan sikap atau perilaku yang dilakukan oleh seorang individu kepada orang lain berdasarkan norma yang berlaku untuk mengatur tingkah laku yang dilakukan dengan etiket atau perilaku baik bertata krama, agar tercipta kenyamanan bagi manusia, dan lingkungan.

Dari kesimpulan karakter dan sopan santun diatas, disimpulkan karakter sopan santun merupakan sekumpulan tata nilai dalam diri manusia yang meliputi tabiat, watak, kebiasaan, budi pekerti, sifat-sifat kejiwaan, kepribadian, dan akhlak yang tertanam dalam jiwa manusia yang membedakan dirinya dengan orang lain dalam bersikap atau berperilaku yang dilakukan oleh manusia.

Perilaku menurunnya karakter sopan santun sering terlihat pada diri siswa, tidak terkecuali siswa SMA. Siswa SMA berada pada kategori masa-masa peralihan dalam dirinya, 


\section{Efektor, Volume 8 Issue 2, 2021, Pages 167-175}

Ula Azizah ${ }^{1}$,Santy Andrianie ${ }^{2}$, Laelatul Arofah ${ }^{3}$

dari remaja awal, remaja pertengahan dan remaja akhir. Batas usia remaja seseorang dibagi menjadi 3 bagian kelompok, yaitu: 1) padausia 12-15 tahun ialah masuk padamasa remaja awal; 2) padausia 15-18 tahun adalah masa remaja pertengahan; 3) pada usia18-21 tahun yaitu masuk pada masa remaja akhir (Monks, dkk., 2006). Pada masa ini seorang remaja akan identik dengan banyaknya sebuah tantangan yang harus diselesaika dan krisis dalam diri. Perubahan masa remaja ini terbagi menjadi 3 aspek, yaitu perubahan biologis, kognitif, dan sosio-emosional. Perubahan biologis antara lain perubahan yang mencakup dari fisik seorang individu; perubahan kognitif antara lain berkaitan dengan pikiran dan intelegensi; serta perubahan sosio-emosional antara lain perubahan individu dengan individu yang lainnya, emosi yang dimilikinya, kepribadian didalam dirinya, serta peran dari konteks sosial dalam masa perkembangan individu tersebut (Santrock, 2011). Dengan adanya berbagai macam jenis perubahan dalam diri individu, dirinya harus mampu mengelola perubahan tersebut agar tidak melakukan tidakan yang melanggar norma berlaku untuk mengatur tingkah laku yang dilakukan dengan etiket atau perilaku baik bertata krama oleh manusia.

Namun pada realitanya fenomena rendahnya karakter sopan santun masih banyak terlihat dilingkungan sekolah, salah satunya pada peserta didik SMA Kelas X yang menunjukkan rendahnya karakter sopan santun pada diri peserta didik, baik dalam kesopanan berbahasa maupun kesopanan dalam berperilaku. Hal ini dibuktikan dengan hasil observsi yang dilakukan oleh pihak tata tertib SMAS Diponegoro Nganjuk didapatkan data yang menyatakan masih terdapatnya siswa yang memiliki karakter sopan santun yang rendah terlihat seperti kurangnya sikap sopan dalam bertutur kata kepada guru atau teman di kelas, kurang bersikap ramah kepada guru atau teman di kelas, kurang memberikan perhatian kepada orang disekitarnya, kurangnya sikap memberi dukungan kepada orang lain, kurang menjaga perasaan orang disekitarnya.

Selain itu, terdapat siswa yang menggunjing teman yang lain, kurangnya sikap ingin membantu kepada orang lain, kurangnya sikap dapat bekerjasama dengan orang lain dalam menyelesaikan sebuah tugas atau kegiatan, kurangnya sikap mengenalikan emosi dalam situasi belajar, kurangnya sikap dapat mengendalikan diri untuk tidak marah, terdapat siswa yang mudah tersinggung akibat perkataan orang lain, kurangnya sikap toleransi antar siswa, dan kurangnya sikap dapat menerima orang lain tanpa syarat. Selain itu, perilaku kurang sopan yang dilakukan oleh siswa diduga kurangnya kontrol dari orang tua, bimbingan dari guru serta tindakan ingin mencoba-coba yang dilakukan oleh siswa (Suryani, 2017).

Dengan adanya beberapa fenomena rendahnya karakter sopan santun diatas, maka perlu ditumbuhkan kembali karakter sopan santun dalam diri siswa. Karakter sopan santun sangat diperlukan bagi peserta didik dalam diri setiap individu. Siswa yang memiliki karakter sopan santun yang tinggi tidak akan melakukan tindakan-tindakan yang menunjukkan menurunnya karakter sopan santun pada dirinya kepada orang disekitarnya.

Menurut Soedarsono (2010) karakter memiliki makna yang amat dalam pada kehidupan manusia, yang artinya manusia mampu untuk menentukan arah tujuan hidup yang ingin dicapainya. Sedangkan sopan santun adalah sifat lembut dan baik seseorang yang dilihat dari bahasa dan perilakunya pada semua orang (Mustari, 2014). Siswa yang memiliki karakter sopan 


\section{Efektor, Volume 8 Issue 2, 2021, Pages 167-175 \\ Ula Azizah ${ }^{1}$,Santy Andrianie ${ }^{2}$, Laelatul Arofah ${ }^{3}$}

santun yang kuat tidak akan membawanya pada penurunan moral dan akan menjadi ciri khas pada diri peserta didik yaitu peserta didik yang berkarakter sopan santun tinggi.

Maka dengan melihat begitu pentingnya siswa memiliki karakter sopan santun membuat peneliti merasa perlu untuk mengembangkan sebuah instrumen yang digunakan sebagai alat untuk memetakan karakter sopan santun siswa SMA kelas $X$ di Nganjuk. Instrumen yang dimaksud dalam penelitian ini berupa skala karakter sopan santun untuk siswa SMA kelas $X$. Dengan adanya skala tersebut diharapkan siswa akan terpetakan karakter sopan santunnya secara valid dan reliabel.

\section{METODE PENELITIAN}

Pengembangan skala karakter sopan santun ini menggunakan langkah-langkah penyusunan instrumen menurut pendapat dari Riduwan (2013:32) yaitu: 1) Mengidentifikasikan variabel yang ada pada rumusan judul penelitian; 2) Menguraikan variabel yang sudah diidentifikasi menjadi sebuah sub variabel; 3) Mencari indikator dimasing-masing sub variabel; 4) Menyusun diskriptor berdasarkan dari masing-masing indikator; 5) Merumuskan masing-masing diskriptor menjadi item-item pernyataan dalam instrumen penelitian; 6) Melengkapi instrumen penelitian dengan tata cara pengisian serta adanya kata pengantar pada instrumen penelitian. Dalam penelitian ini hasil skala karakter sopan santun dianalisis menggunakan korelasi product moment sedangkan untuk perhitungan reliabilitas denganmenggunakan alpha cronbach yang dalam penganalisisan uji validitas dan uji reliabilitas dianalisis dengan alat bantu bantuan software SPSS.21.0.

Dalam penelitian karakter sopan santun ini, peneliti memodifikasi langkah-langkah penyusunan instrumen menurut Ridwan sesuai dengan kebutuhan penelitian. Beberapa tahapan penelitian, meliputi: 1) Peneliti mengidentifikasi variabel yang akan dikembangkan dalam penelitian, kemudian dibuat sebagai skala psikologis, yaitu karakter sopan santun; 2) Peneliti menentukan indikator berdasarkan variabel, indikator dalam penelitian ini diambil dan diadopsi dari penelitian Aminah (2019) dengan judul "Peran Guru dalam Peningkatan Karakter Disiplin dan Sopan Santun Siswa"; 3) Peneliti mengurutkan prediktor dari setiap indikator dan merumuskannya menjadi item-item pernyataan. Dalam penelitian ini indikator pertama terdiri dari 2 prediktor dan 8 item pernyataan. Indikator kedua terdiri dari 2 prediktor dan 8 item pernyataan. Indikator ketiga terdiri dari 2 prediktor dan 8 item pernyataan. Indikator keempat terdiri dari 2 prediktor dan 8 item pernyataan. Indikator kelima terdiri dari 2 prediktor dan 8 item pernyataan. Indikator keenam terdiri dari 2 prediktor dan 8 item pernyataan; 4) Peneliti melengkapi skala karakter sopan santun dengan tata cara pengisian dan kata pengantar untuk siswa SMA kelas X. Skala karakter sopan santun ini terdiri dari 48 item pernyataan. Selanjutnya peneliti melakukan uji validitas dengan menggunakan korelasi product moment dan uji reliabilitas dengan menggunakan alpha cronbach. Skala karakter sopan santun ini terlebih dahulu diuji coba secara terbatas di SMAS Diponegoro Nganjuk. Peneliti menggunakan 30 siswa SMA kelas X untuk mengetahui bagaimana tingkat dari validitas dan reliabilitas instrumen penelitian yang sudah dikembangkan. 
Efektor, Volume 8 Issue 2, 2021, Pages 167-175

Ula Azizah¹,Santy Andrianie², Laelatul Arofah ${ }^{3}$

HASIL DAN PEMBAHASAN

Hasil

Dibawah ini hasil uji awal validitas dan reliabilitas skala karakter sopan santun dengan bantuan software SPSS.21.0.

Tabel 1. Analisis Butir Tahap Awal Skala Karakter Sopan Santun

\begin{tabular}{|c|c|c|c|}
\hline $\begin{array}{c}\text { No } \\
\text { Item }\end{array}$ & $r_{\text {tabel }}$ & $r_{\text {hitung }}$ & Keterangan \\
\hline 1 & 0,374 & $0.597^{* *}$ & Diterima \\
\hline 2 & 0,374 & $0.723^{* *}$ & Diterima \\
\hline 3 & 0,374 & 0,207 & Tidak Diterima \\
\hline 4 & 0,374 & 0,273 & Tidak Diterima \\
\hline 5 & 0,374 & $0,361^{*}$ & Tidak Diterima \\
\hline 6 & 0,374 & $0.589^{* *}$ & Diterima \\
\hline 7 & 0,374 & $0.405^{*}$ & Diterima \\
\hline 8 & 0,374 & $0.633^{* *}$ & Diterima \\
\hline 9 & 0,374 & 0,345 & Tidak Diterima \\
\hline 10 & 0,374 & $0.692^{* *}$ & Diterima \\
\hline 11 & 0,374 & $0.539^{* *}$ & Diterima \\
\hline 12 & 0,374 & $0.550^{* *}$ & Diterima \\
\hline 13 & 0,374 & 0,306 & Tidak Diterima \\
\hline 14 & 0,374 & $0.553^{* *}$ & Diterima \\
\hline 15 & 0,374 & 0,088 & Tidak Diterima \\
\hline 16 & 0,374 & $0.553^{* *}$ & Diterima \\
\hline 17 & 0,374 & 0,278 & Tidak Diterima \\
\hline 18 & 0,374 & $0.524^{* *}$ & Diterima \\
\hline 19 & 0,374 & 0,227 & Tidak Diterima \\
\hline 20 & 0,374 & $0.646^{* *}$ & Diterima \\
\hline 21 & 0,374 & $0.376^{*}$ & Diterima \\
\hline 22 & 0,374 & $0.566^{* *}$ & Diterima \\
\hline 23 & 0,374 & $0.597^{* *}$ & Diterima \\
\hline 24 & 0,374 & $0.582^{* *}$ & Diterima \\
\hline
\end{tabular}

\begin{tabular}{|c|c|c|c|}
\hline $\begin{array}{c}\text { No } \\
\text { Item }\end{array}$ & $r_{\text {tabel }}$ & $r_{\text {hitung }}$ & Keterangan \\
\hline 25 & 0,374 & 0,192 & Tidak Diterima \\
\hline 26 & 0,374 & $0.401^{*}$ & Diterima \\
\hline 27 & 0,374 & $0.540^{* *}$ & Diterima \\
\hline 28 & 0,374 & $0,558^{* *}$ & Diterima \\
\hline 29 & 0,374 & 0,244 & Tidak Diterima \\
\hline 30 & 0,374 & $0.541^{* *}$ & Diterima \\
\hline 31 & 0,374 & $0-, 015$ & Tidak Diterima \\
\hline 32 & 0,374 & 0,333 & Tidak Diterima \\
\hline 33 & 0,374 & $0-, 141$ & Tidak Diterima \\
\hline 34 & 0,374 & $0.499^{* *}$ & Diterima \\
\hline 35 & 0,374 & $0-, 083$ & Tidak Diterima \\
\hline 36 & 0,374 & $0.455^{*}$ & Diterima \\
\hline 37 & 0,374 & $0-, 256$ & Tidak Diterima \\
\hline 38 & 0,374 & $0.603^{* *}$ & Diterima \\
\hline 39 & 0,374 & 0,200 & Tidak Diterima \\
\hline 40 & 0,374 & $0.543^{* *}$ & Diterima \\
\hline 41 & 0,374 & $0.461^{*}$ & Diterima \\
\hline 42 & 0,374 & $0.688^{* *}$ & Diterima \\
\hline 43 & 0,374 &, 0171 & Tidak Diterima \\
\hline 44 & 0,374 & $0.562^{* *}$ & Diterima \\
\hline 45 & 0,374 & 0,216 & Tidak Diterima \\
\hline 46 & 0,374 & $0.665^{* *}$ & Diterima \\
\hline 47 & 0,374 & 0,354 & Tidak Diterima \\
\hline 48 & 0,374 & $0.466^{* *}$ & Diterima \\
\hline
\end{tabular}

Berlandaskan tabel 1 diatas yang dianalisis dengan bantuan alat bantu software SPSS.21.0 diatas, didapatkan hasil bahwa terdapat 19 item yang tidak diterima atau tidak valid, yang berarti item tersebut gugur. Item-item yang tidakditerima atau tidak valid diantaranya $3,4,5$, $9,13,15,17,19,25,29,31,32,33,35,37,39,43,45,47$. Setelah item-item yang tidak diterima atau tidak valid dihapus. Item pernyataan dikatakan diterima atau valid jika $r$ hitung $>r$ tabel maka valid, dengan didapatkan $r$ tabel 0,374 . Valid atau diterima dan tidaknya sebuah item pernyataan dapat diketahui dengan melihat perbandingan indeks korelasi product moment pearson dengan taraf signifikansi $5 \%(0,05)$ pada distribusi nilai $r$ tabel. Jika $r$ hitung lebih besar dari $r$ tabel maka pernyataan itu diterima atau valid dan sebaliknya (Ghozali, 2005) dengan $r$ hitung $r$ tabel untuk derajat kebebasan n-2. Dibawah ini hasil uji validitas yang menunjukkan seluruh item-item pernyataan valid. 
Efektor, Volume 8 Issue 2, 2021, Pages 167-175

Ula Azizah¹,Santy Andrianie², Laelatul Arofah ${ }^{3}$

Tabel 2. Analisis Butir Tahap Akhir Skala Karakter Sopan Santun

\begin{tabular}{c|l|l|l|}
\hline $\begin{array}{c}\text { No } \\
\text { Item }\end{array}$ & $r_{\text {tabel }}$ & $r_{\text {hitung }}$ & Keterangan \\
\hline 1 & 0,374 & $0.597^{* *}$ & Diterima \\
\hline 2 & 0,374 & $0.723^{* *}$ & Diterima \\
\hline 6 & 0,374 & $0.589^{* *}$ & Diterima \\
\hline 7 & 0,374 & $0.405^{*}$ & Diterima \\
\hline 8 & 0,374 & $0.633^{* *}$ & Diterima \\
\hline 10 & 0,374 & $0.692^{* *}$ & Diterima \\
\hline 11 & 0,374 & $0.539^{* *}$ & Diterima \\
\hline 12 & 0,374 & $0.550^{* *}$ & Diterima \\
\hline 14 & 0,374 & $0.553^{* *}$ & Diterima \\
\hline 16 & 0,374 & $0.553^{* *}$ & Diterima \\
\hline 18 & 0,374 & $0.524^{* *}$ & Diterima \\
\hline 20 & 0,374 & $0.646^{* *}$ & Diterima \\
\hline 21 & 0,374 & $0.376^{*}$ & Diterima \\
\hline 22 & 0,374 & $0.566^{* *}$ & Diterima \\
\hline 23 & 0,374 & $0.597^{* *}$ & Diterima \\
\hline
\end{tabular}

\begin{tabular}{c|c|c|c|}
\hline $\begin{array}{c}\text { No } \\
\text { Item }\end{array}$ & $r_{\text {tabel }}$ & $r_{\text {hitung }}$ & Keterangan \\
\hline 24 & 0,374 & $0.582^{* *}$ & Diterima \\
\hline 26 & 0,374 & $0.401^{*}$ & Diterima \\
\hline 27 & 0,374 & $0.540^{* *}$ & Diterima \\
\hline 28 & 0,374 & $0.558^{* *}$ & Diterima \\
\hline 30 & 0,374 & $0.541^{* *}$ & Diterima \\
\hline 34 & 0,374 & $0.499^{* *}$ & Diterima \\
\hline 36 & 0,374 & $0.455^{*}$ & Diterima \\
\hline 38 & 0,374 & $0.603^{* *}$ & Diterima \\
\hline 40 & 0,374 & $0.543^{* *}$ & Diterima \\
\hline 41 & 0,374 & $0.461^{*}$ & Diterima \\
\hline 42 & 0,374 & $0.688^{* *}$ & Diterima \\
\hline 44 & 0,374 & $0.562^{* *}$ & Diterima \\
\hline 46 & 0,374 & $0.665^{* *}$ & Diterima \\
\hline 48 & 0,374 & $0.466^{* *}$ & Diterima \\
\hline
\end{tabular}

Berdasarkan uji coba validitas keseluruhan instrumen skala karakter sopan santun yang berjumlah 48 item pernyataan, diketahui ada 19 item pernyataan yang tidak diterima atau tidak valid. Item pernyataan dikatakan tidak valid jika $r$ hitung $r$ tabel maka tidak valid. Item-item pernyataan yang tidak diterima atau tidak valid akan digugurkan dan tidak diikutsertakan dalam analisis tahap berikutnya. Berikut hasil analisis reliabilitas terhadap 29 item valid adalah sebagai berikut:

Tabel 3. Analisis reliabilitasSkala Karakter Sopan Santun

Reliability Statistics

\begin{tabular}{|r|r|}
\hline $\begin{array}{c}\text { Cronbach's } \\
\text { Alpha }\end{array}$ & $\begin{array}{c}\mathrm{N} \text { of } \\
\text { Items }\end{array}$ \\
\hline, 928 & 29 \\
\hline
\end{tabular}

Berdasarkan tabel hasil uji reliabilitas skala karakter sopan santun diatas, diperoleh hasil analisis reliabilitas $r$ alpha 0,928 yang berarti berada pada kategori tinggi. Maka, skala karakter sopan santun siap untuk digunakan untuk pemetaan tingkat karakter sopan santun siswa SMA kelas $X$ di Nganjuk. Selanjutnya peneliti merevisi kisi-kisi skala karakter sopan santun berdasarkan item pernyataan yang sudah diterima atau valid. Dari hasil uji validitas dan reliabilitas yang sudah dilaksanakan, didapatkan 29 item pernyataan diterima atau valid dan reliabel yang dapat digunakan sebagai pijakan dalam pemetaan tingkat karakter sopan santun siswa SMA kelas $X$ di Nganjuk. 


\section{Efektor, Volume 8 Issue 2, 2021, Pages 167-175}

Ula Azizah ${ }^{1}$,Santy Andrianie ${ }^{2}$, Laelatul Arofah ${ }^{3}$

\section{Pembahasan}

Dari kesimpulan mengenai pengertian karakter sopan santun, peneliti menjadikannya sebagai patokan dalam mengembangkan skala karakter sopan santun siswa SMA kelas $X$ di Nganjuk. Peneliti menyusun skala karakter sopan santun ini dengan mengambil dan mengadopsi indikator dari penelitian Aminah (2019) peneliti mengembangkan prediktor yang dikembangkan menjadi item pernyataan skala karakter sopan santun berdasarkan dari indikator, selanjutnya di uji validitas dan reliabilitas. Berdasarkan hasil uji validitas yang sudah dilakukan, didapatkan 29 item valid, dan 19 item tidak valid. Selanjutnya, berdasarkan uji reliabilitas didapatkan tingkat reliabilitasnya sebesar 0, 928 yang berarti berada dalam kategori tinggi. Menurut Azwar (dalam Arofah, 2017) dikatakan reliabel memuaskan jika capaian koefisien sejumlah 0,9 atau lebih.

Karakter sopan santun pada diri siswa sangat perlu untuk diperhatikan agar tidak adanya siswa yang melakukan tindakan-tidakan yang mengarah pada penurunan karakter sopan santun dalam dirinya dan menjadi komponen penting dalam mencapai keberhasilan diri siswa. Rendahnya sopan santun peserta didik kepada guru atau orang yang lebih tua, juga diperkuat dengan hasil penelitian yang dilakukan oleh Sujiyanto (dalam Kholifah \& Naimah T, 2017) padapeserta didikkelas XI SMA Negeri Rembang Purbalingga yang berjumlah 36 siswa, menunjukkan adanya 13 peserta didik memiliki tingkat sopan santun yang masih rendah terhadap guru atau orang yang lebih tua. Dengan adanya permasalah ini memperkuat peneliti untuk mengembangkan instrumen yang digunakan sebagai alat alat ukur yang valid dan reliabel.

Dalam penelitian ini indikator pertama meliputi bersikap ramah dan sopan kepada siapa saja terdiri dari 2 prediktor dan 8 item pernyataan. Indikator kedua yaitu memberikan perhatian kepada orang lain terdiri dari 2 prediktor dan 8 item pernyataan. Indikator ketiga yaitu berusaha selalu menjaga perasaan orang lain terdiri dari 2 prediktor dan 8 item pernyataan. Indikator keempat yaitu bersikap ingin membantu terdiri dari 2 prediktor dan 8 item pernyataan. Indikator kelima yaitu dapat menguasi diri dan mengendalikan emosi dalam situasi apapun terdiri dari 2 prediktor dan 8 item pernyataan. Indikator keenam yaitu memiliki rasa toleransi yang tinggi terdiri dari 2 prediktor dan 8 item pernyataan.

Instrumen adalah alat yang digunakan dalam proses pengumpulan data dari suatu variabel. Menurut Sugiyono (2013), instrumen adalah alat ukur yang dapat digunakan untuk memperoleh suatu yang mencakup data kuantitatif yang membahas mengenai variasi karakteristik dari sebuah variabel secara objektif. Matondang (dalam Arofah, 2021). Jika suatu instrumen itu diterima atau valid dan reliabel, maka dapat dikatakan bahwa instrumen itu baik. Dapat dikatakan suatu instrumen berada pada kedudukan penting, jika instrumen tersebut dapat digunakan dalam proses pengambilan sebuah data (Yusup, 2018). Skala karakter sopan ini akan membantu peneliti kedepannya untuk melihat sejauhmana tingkat karakter sopan santun yang ada pada siswa. Dengan hal ini, maka peneliti akan mengetahui siswa mana yang akan diberikan treatment untuk meningkatkan kembali karakter sopan santun pada diri siswa. Meningkatkan kembali karakter sopan santun dalam diri siswa sangat penting, karena siswa yang memiliki karakter sopan santun dirinya akan dapat dengan mudah diterima orang lain dan dihargai orang. 


\section{Efektor, Volume 8 Issue 2, 2021, Pages 167-175 \\ Ula Azizah 1 ,Santy Andrianie2 ${ }^{2}$, Laelatul Arofah ${ }^{3}$}

\section{SIMPULAN}

Berdasarkan hasil analisis instrumen skala karakter sopan santun dengan menggunakan enam langkah penyusunan instrumen dari Riduwan yang dimodifikasi diatas uji validitas dan reliabilitas dengan menggunakan korelasi product moment dan alpha cronbach diperoleh 29 item pernyataan valid dengan reliabilitas $r$ alpha sebesar 0,928 berarti berada dalam kategori tinggi yang artinya skala karakter sopan santun dapat digunakan oleh guru BK untuk memetakan karakter sopan santun siswa SMA kelas $\mathrm{X}$.

\section{DAFTAR RUJUKAN}

Arofah, L. (2021). Validitas Dan Reliabilitas Skala Displin Diri Untuk Siswa Sekolah Menengah Pertama. Nusantara of Research : Jurnal Hasil-Hasil Penelitian Universitas Nusantara PGRI Kediri, 8(1), 25-34. https://doi.org/10.29407/nor.v8i1.15873

Aminah, S. (2019). Peran Guru dalam Peningkatan Karakter Disiplin dan Sopan Santun Siswa Kelas IV SDN Karangono 02 Kecamatan Tambakbromo Kabupaten Pati. (Online). tersedia: http://lib.unnes.ac.id/33496/1/1401415177_Optimized.pdf, diunduh 19 Juni 2021.

Bertens, K. (2013). Etika. Yogyakarta: PT Kanisius.

Fitri, A. Z. (2017). Pendidikan Karakter Berbasis Nilai \& Etika di Sekolah. Jogjakarta: Ar-Ruzz Media.

Ghozali, Imam. (2005). Aplikasi Analisis Multivariate dengan SPSS. Semarang: Badan Penerbit UNDIP.

Ghozali, Imam. (2011). Aplikasi Analisis Multivariate Dengan Program IBM SPSS19, Semarang: Badan Penerbit Universitas Diponegoro.

Kholifah \& Naimah T.(2017). Studi Tentang Sopan Santun Pada Peserta Didik. Jurnal Sains Sosial dan Humaniora, 1(1), 1-9. http://dx.doi.org/10.30595/jssh.v1i1.1036

Larasati. (2020). Peran Orang Tua Dalam Membentuk karakter Sopan Santun Anak Atas Dampak Media Sosial (Studi Kasus Siswa Kelas IV Di SDN 1 Jenangan). (Online). tersedia:

http://etheses.iainponorogo.ac.id/11973/1/SKRIPSI_LARASATI_210616158.pdf, diunduh 18 Juni 2021.

Mansur, Muslich. (2011). Pendidikan Karakter : Menjawab Tantangan Krisis Multidimensional, Jakarta; Bumi Aksara.

Monks, F. J., Knoers, A. M. P., \& Haditono, S. R. (2006). Psikologi Perkembangan: Pengantar dalam Berbagai Bagiannya. Yogyakarta: Gadjah Mada University Press.

Mustari, M. (2014). Nilai Karakter Refleksi untuk Pendidikan. Jakarta: Rajawali Pers.

Poerwadarminta. (2007). Kamus Umum Bahasa Indonesia, Jakarta, Balai Pustaka.

Riduwan. Skala Pengukuran Variabel-variabel Penelitian. Bandung: ALFABETA.

Santrock, J. W. (2011). Masa Perkembangan Anak (Edisi Kesebelas). Jakarta: Salemba Humanika.

Soedarsono, S. (2010). Karakter Mengantar Bangsa dari Gelap Menuju Terang (Edisi Revisi). Jakarta: PT Gramedia.

Sugiyono. (2013). Metode Penelitian Kuantitatif, Kualitatif, dan R\&D. Bandung: CV Alfabeta

Suryani, L. (2017). Upaya Meningkatkan Sopan Santun Berbicara dengan Teman Sebaya Melalui BImbingan Kelompok. E-Journal Mitra Pendidikan, 01(1), 112-124.

Yusup, F. (2018). Uji Validitas Dan Reliabilitas Instrumen Penelitian Kuantitatif. Jurnal Tarbiyah: Jurnal IImiah Kependidikan, 7 (1): 17-23.

Zubaedi, (2011). Desain Pendidikan Karakter: Konsepsi dan Aplikasinya dalam Lembaga Pendidikan, Jakarta: Kencana. 
Efektor, Volume 8 Issue 2, 2021, Pages 167-175

Ula Azizah¹,Santy Andrianie², Laelatul Arofah ${ }^{3}$

Zuriah, N. (2007). Pendidikan Moral \& Budi Pekerti dalam Perspektif Perubahan. Jakarta: Bumi Aksara. 